GARCIA, J., \& KOELLING, R. A. The relation of cue to consequence in avoidance learning. Psychonomic Science. $1966,4,123-124$.

KIMBLE, G. A. Hilgard and Marquis' Conditioning and learning. New York: Appleton-Century-Crofts. 1961.

M CLAURIN. W. A. Post irradiation saccharin avoidance in rats as a function of the interval between ingestion and exposure. Journal of Comparative \& Physiological Psychology, 1964, 57, 316-317.

RAZRAN, G. The dominance-continguity theory of the acquisition of classical conditioning. Psychological Bulletin, $1957,54,1-46$.

REVUSKY, S. H. Aversion to sucrose produced by contingent $X$-irradiation:
Temporal and Dosage Parameters. Joumal of Comparative $\&$ Physiological Psychology, 1968, 65, 17-22.

ROZIN, P. Specific aversions and neophobia resulting from vitamin deficiency or poisoning in half-wild and domestic rats. Journal of Comparative \& Phyiological Psychology, 1968, 66, 82-88.

SCHAEFER, V. H. Differences between strains of rats in avoidance conditioning without an explicit warning stimulus. Journal of Comparative \& Physiological Psychology, 1959, 52, 120-122.

WINER, B. J. Statistical principles in experimental design. New York: McGraw-Hill, 1962.

WRIGHT, W. E., FOSHEE, D. P., \& MCCLEARY, G. E. Comparison of taste-aversion with various delays and cyclophosphamide dose levels. Psychonomic Science, 1971, 22, 55-56.

\title{
Response-reinforcement interactions in multiple interval schedules
}

\author{
RONALD G. HUGHES * \\ University of North Carolina at Greensboro, Greensboro, N.C. 27405
}

After responding was maintained on multiple variable-interval schedules of reinforcement, a limited-hold requirement was added to one component. Each scheduled availability of reinforcement terminated if no response occurred within a 1-sec period of time. Response rate increased and reinforcement rate decreased in the limited-hold component. Response rate in the unchanged VI component increased. When responding was extinguished in the changed component, positive behavioral contrast was observed in the unchanged VI component.

In variable interval (VI) schedules of reinforcement, changes in reinforcement rates produce direct changes in response rates. When two VI schedules alternate in a multiple schedule, changes in reinforcement rate in one component, while producing direct changes in that component, produce inverse changes in responding in an unaltered component. These opposing changes in response rates have been termed behavioral contrast (Reynolds, 1961). It has since been demonstrated (Hughes, 1970) that these changes in response rates will occur in the absence of large changes in responding in the component in which reinforcement rate is varied. The importance of reinforcement rate in these interactions has been stressed by Bloomfield (1967). Arranging multiple schedules with a constant VI 1-min schedule in one comporant, S1, and either a fixed ratio (FR) schedule or a DRL schedule in the other component, S2, Bloomfield demonstrated that equivalent changes in the frequency of reinforcement in S2 resulted in similar effects on response rate in $S 1$, regardless of whether the schedule in S2 led to high

* Research conducted at the University of Maryland and supported by USPHS Grant No. MH-01604-13 from the National Institute of Mental Health to the University of Maryland.

rates of responding on $\mathrm{FR}$ or to low rates on DRL.

Reynolds \& Limpo (1968) have reported that positive behavioral contrast will occur in multiple DRL schedules when, upon the addition of an added "clock" to one DRL component, responding is reduced and reinforcement frequency simultaneously increased in that component. While cited as support of a reduction in responding as a factor in producing positive contrast, a reinforcement interpretation can be saved if one chooses to treat the reinforced response as pausing rather than keypecking. Thus, the increased pausing that develops in the component with the added clock is contrasted (negative contrast) with the occurrence of shorter pauses (resulting in higher response rates) in the unchanged DRL component.

Reynolds \& Limpo (1968) have pointed to the lack of data on a potentially fundamental case of contrast in multiple schedules: the effect on responding in an unchanged component produced by a substantial increase in response rate together with a substantial decrease in reinforcement rate. These conditions were satisfied in the present experiment by the addition of a limited hold requirement to one component of a multiple variable-interval schedule of reinforcement. The primary observation was the rate of responding in the unchanged variable-interval component.

\section{SUBJECTS}

Two adult Silver King pigeons with previous experimental histories were maintained at approximately $80 \%$ of their free-feeding weights. Animals were housed in individual cages with free access to water. Daily experimental sessions were run.

\section{APPARATUS}

A standard two-key experimental chamber for pigeons similar in design to that described by Ferster \& Skinner (1957) was used. The right key was covered throughout the experiment. The left key could be transilluminated with either a red or green light, and was effectively operated by a force of $15 \mathrm{~g}$. No feedback relay was used. White noise masked extraneous sounds. Reinforcement consisted of a 4.5 -sec access to mixed grain. Reinforcements were programmed by variable-interval tapes consisting of 13 intervals arranged in an irregular order. Standard relay programming equipment was located in an adjoining room.

\section{PROCEDURE}

Two pigeons were initially exposed to multiple variable-interval schedules of reinforcement, in which $3-\mathrm{min}$ components of red regularly alternated with 3-min components of green illumination of the response key. Responding was reinforced in each component according to identical arithmetic VI 1-min schedules, a daily session consisting of 10 presentations of each schedule component. When responding was approximately equal in both components, a limited hold 1 -sec requirement was added to the red component. Each scheduled availability of reinforcement terminated if no response occurred within a 1 -sec period of time. Bird RH-1 was exposed to this condition for 14 daily sessions and Bird RH-3 for 10 daily sessions. No changes were made in the regularly alternated green component. The limited hold requirement was then removed and the schedule in the red component changed to VI $2 \mathrm{~min}$. This condition was in effect for 9 sessions for RH-1 and 9 sessions for RH-3. Responding was then extinguished in the red component.

\section{RESULTS}

Figure 1 shows the response rates in each schedule component for each of the experimental conditions. Table 1 gives the obtained mean rates of reinforcement in the red component for each experimental condition. Panel A of Fig. 1 shows the rate of responding in each VI component for the five sessions preceding the 

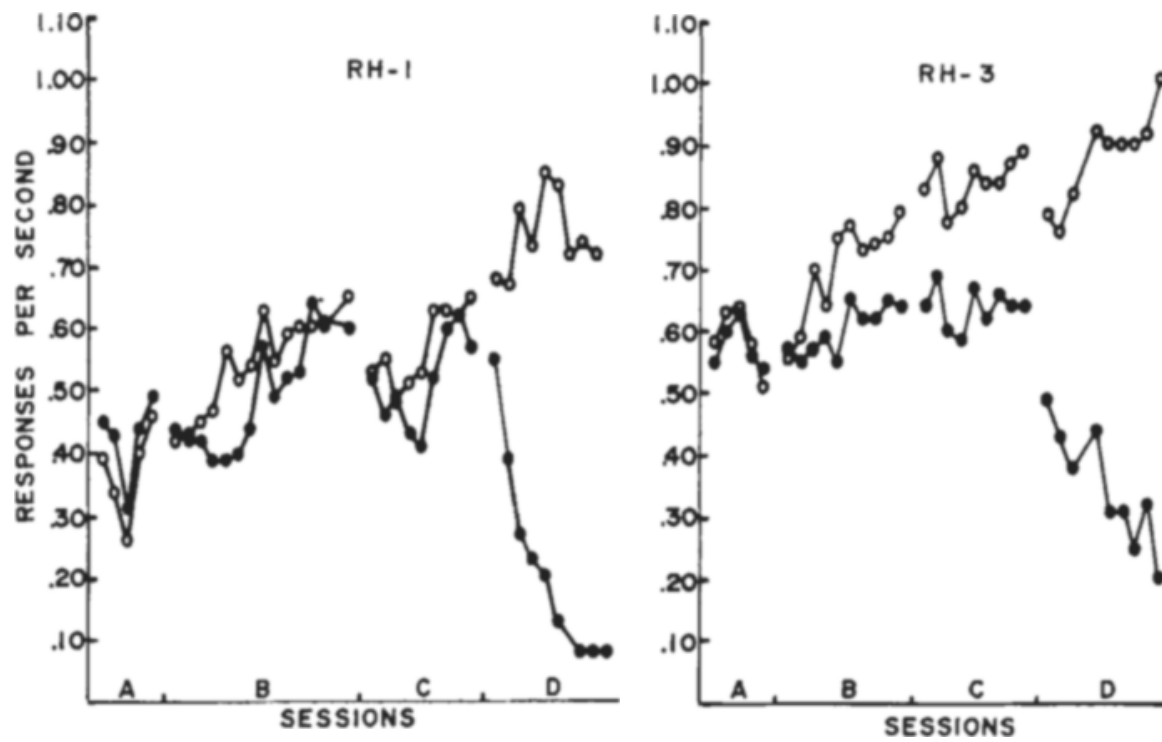

Fig. 1. Absolute response rates per session in each component of the multiple schedule (see text for details). Closed circles, red component; open circles, green component.

introduction of the limited hold requirement. Table 1 shows that the mean rates of reinforcement in the red component were $.96 \mathrm{rft} / \mathrm{min}$ and $.97 \mathrm{rft} / \mathrm{min}$ for Birds $\mathrm{RH}-1$ and $\mathrm{RH} \cdot 3$, respectively.

The effects of the introduction of the limited hold requirement are seen in Panel B of the figure. The introduction of the limited hold requirement produced an immediate and substantial decrease in reinforcement rate in the red component. Day-to-day comparisons of reinforcement rates in the limited hold component revealed numerous reversals. However, when the reinforcement rates from the first half of the limited hold sessions were grouped together and likewise the rates for the second half of the sessions, a clear increase was seen over sessions. Initial effects on rates of responding in the limited hold component were different for the two birds. For Bird RH-1 a decrease in responding occurred which was sustained for approximately seven sessions before a change to a higher rate of responding occurred. For Bird RH-3 no apparent changes in responding occurred for the first five sessions following the introduction

of the limited hold despite the fact that a substantial decrease in reinforcement rate occurred in that component. As for Bird $\mathrm{RH}-1$, a rather sudden shift to a higher rate of responding occurred after approximately five sessions. Response rates in the green unchanged VI component increased for both birds, with the mean response rates for the last 5 days of the limited hold condition showing increases of $65 \%$ and $29 \%$ over the mean rates of the preceding condition in Panel A.

The change in Panel $C$ from mult VI-1 VI-1 to mult VI-1 VI-2 was intended to assess the effect of removing the limited hold requirement without changing reinforcement rate. This was not accomplished, as reinforcement rate for both birds decreased below that of the preceding condition. The effects of this decrease were different for the two birds. For Bird $\mathrm{RH}-1$ the decrease in reinforcement rate was accompanied by a decrease in response rate, while for Bird RH-3 no changes in response rate occurred. The general effect in the unchanged component was induction for Bird RH-1, while for RH-3 the further decrease in reinforcement rate produced a further increase in

Table 1 Mean Obtained Rates of Reinforcement in Red VI Component

\begin{tabular}{|c|c|c|c|c|}
\hline \multirow[b]{2}{*}{ Condition } & \multicolumn{2}{|c|}{ RH-1 } & \multicolumn{2}{|c|}{$\mathbf{R} \mathbf{H} \cdot \mathbf{3}$} \\
\hline & $\mathrm{Rft} / \mathrm{Min}$ & Sessions & $\mathrm{Rft} / \mathrm{Min}$ & Sessions \\
\hline $\begin{array}{l}\text { A. Mult VI-1 VI-1 } \\
\text { B. Mult VI-1 VI-1 (limited hold) } \\
\text { C. Mult VI-1 VI-2 } \\
\text { D. Mult VI-1 EXT }\end{array}$ & $\begin{array}{r}.96 \\
.42 \\
.61 \\
.50 \\
0.00\end{array}$ & $\begin{array}{l}\mathbf{5} \\
7 \\
\mathbf{7} \\
\mathbf{9} \\
\mathbf{9}\end{array}$ & $\begin{array}{r}.97 \\
.54 \\
.70 \\
.50 \\
0.00\end{array}$ & $\begin{array}{l}\mathbf{5} \\
\mathbf{5} \\
\mathbf{5} \\
\mathbf{9} \\
\mathbf{9}\end{array}$ \\
\hline
\end{tabular}

response rate in the unchanged component.

When reinforcement was discontinued for responding in the red component, responding in the red component decreased for both birds (Panel D). Positive behavioral contrast occurred in the unchanged VI component for Bird RH-1 and to a lesser extent for Bird RH-3. The reason for the initial decrease in responding in the unchanged component in Bird RH-3 is not apparent at the present time.

\section{DISCUSSION}

The present data offer strong support for the importance of changes in reinforcement rates in producing response-rate changes in the unchanged component of multiple VI schedules. Although response rates in the component with the limited hold requirement increased substantially for Bird RH-1 and to a considerably lesser extent for Bird $\mathrm{RH}-3$, conclusive evidence for a limited hold effect was not demonstrated in the present experiment. Because reinforcement rates were not held constant from Condition B to Condition C, it cannot be determined whether the decrease in responding for Bird $\mathrm{RH}-1$ in Condition $\mathrm{C}$ was due to the removal of the limited hold contingency or to the decrease in reinforcement rate. Except for Condition D, Bird RH-3 appears to have been generally insensitive to both manipulations. It was not, therefore, possible to completely separate reinforcement rate effects from possible limited hold effects.

More importantly, however, in all instances except in Condition $\mathrm{C}$ for Bird $\mathrm{RH}-1$ (where response induction occurred), support was given for the inverse relationship between responding in an unchanged component and reinforcement rate in a varied component. Conditions $B$ and $\mathrm{D}$ for both birds showed that whether response rate increased (as in B) or decreased (as in D), a reduction in reinforcement rate produced an increase in responding in the unaltered component of the multiple schedule.

\section{REFERENCES}

BLOOMFIELD, T M Behavioral contrast and relative reinforcement frequency in two multiple schedules. Journal of the Experimental Analysis of Behavior, 1967. 10, 151-155.

FERSTER C B \& SKINNER, B. F Schedules of reinforcement. New York: Appleton-Century-Crofts, 1957.

HUGHES, R. G. The effects of signalled reinforcement in multiple schedules of reinforcement. Unpublished master's thesis, University of North Carolina at Greensboro, 1970.

REYNOLDS, G. S. Behavioral contrast. Journal of the Experimental Analysis of Behavior, 1961, 4, 57-71.

REYNOLDS, G. S., \& LIMPO, A. J. Some causes of behavioral contrast. Journal of the Experimental Analysis of Behavior. $1968,11,543-547$. 